Louisiana State University

LSU Digital Commons

Faculty Publications

Department of Physics \& Astronomy

8-24-2007

\title{
Exchange bias behavior in Ni-Mn-Sb Heusler alloys
}

Mahmud Khan

Southern Illinois University Carbondale

Igor Dubenko

Southern Illinois University Carbondale

Shane Stadler

Southern Illinois University Carbondale

Naushad Ali

Southern Illinois University Carbondale

Follow this and additional works at: https://digitalcommons.Isu.edu/physics_astronomy_pubs

\section{Recommended Citation}

Khan, M., Dubenko, I., Stadler, S., \& Ali, N. (2007). Exchange bias behavior in Ni-Mn-Sb Heusler alloys. Applied Physics Letters, 91 (7) https://doi.org/10.1063/1.2772233

This Article is brought to you for free and open access by the Department of Physics \& Astronomy at LSU Digital Commons. It has been accepted for inclusion in Faculty Publications by an authorized administrator of LSU Digital Commons. For more information, please contact ir@lsu.edu. 


\section{Southern Illinois University Carbondale OpenSIUC}

\section{Exchange Bias Behavior in Ni-Mn-Sb Heusler Alloys}

Mahmud Khan

Southern Illinois University Carbondale

Igor Dubenko

Southern Illinois University Carbondale

Shane Stadler

Southern Illinois University Carbondale

Naushad Ali

Southern Illinois University Carbondale

Follow this and additional works at: http://opensiuc.lib.siu.edu/phys_pubs

(C) 2007 American Institute of Physics

Published in Applied Physics Letters, Vol. 91 No. 7 (2007) at doi: 10.1063/1.2772233

\section{Recommended Citation}

Khan, Mahmud, Dubenko, Igor, Stadler, Shane and Ali, Naushad. "Exchange Bias Behavior in Ni-Mn-Sb Heusler Alloys." (Aug 2007).

This Article is brought to you for free and open access by the Department of Physics at OpenSIUC. It has been accepted for inclusion in Publications by an authorized administrator of OpenSIUC. For more information, please contact opensiuc@lib.siu.edu. 


\title{
Exchange bias behavior in $\mathrm{Ni}-\mathrm{Mn}-\mathrm{Sb}$ Heusler alloys
}

\author{
Mahmud Khan,, Igor Dubenko, Shane Stadler, and Naushad Ali \\ Department of Physics, Southern Illinois University, Carbondale, Illinois 62901
}

(Received 3 July 2007; accepted 25 July 2007; published online 16 August 2007)

\begin{abstract}
The authors report the observation of exchange bias in bulk polycrystalline $\mathrm{Ni}_{50} \mathrm{Mn}_{25+x} \mathrm{Sb}_{25-x}$ Heusler alloys. Shifts in hysteresis loops of up to 248 Oe were observed in the $5 \mathrm{~T}$ field cooled samples. The observed exchange bias behavior in $\mathrm{Ni}_{50} \mathrm{Mn}_{25+x} \mathrm{Sb}_{25-x}$ is attributed to the coexistence of antiferromagnetic and ferromagnetic exchange interactions in the system. Such behavior is an addition to the multifunctional properties of the $\mathrm{Ni}_{50} \mathrm{Mn}_{25+x} \mathrm{Sb}_{25-x}$ Heusler alloy system.
\end{abstract}

(C) 2007 American Institute of Physics. [DOI: 10.1063/1.2772233]

In 1956, Meiklejohn and Bean discovered a type of magnetic anisotropy in fine particles of cobalt coated with cobalt oxide. ${ }^{1}$ In their discovery, they found a shift in the zero field cooled (ZFC) and field cooled (FC) hysteresis loops of the oxide coated particles. Since the discovery of this phenomenon, which is now known as exchange bias (EB), extensive research has been done on this subject, both experimentally and theoretically. ${ }^{2-12}$ The outcomes of these efforts are the discovery of many different materials exhibiting EB properties. ${ }^{8}$ Over the years, materials possessing EB properties have been utilized significantly in many technological devices including permanent magnets, ${ }^{8}$ magnetic recording media, ${ }^{9,10}$ sensors, read heads, and many other devices. ${ }^{8}$ Usually, EB is observed in systems containing ferromagnetic (FM)-antiferromagnetic (AF) interfaces, such as in small coated particles, inhomogeneous materials, and thin films. ${ }^{8}$

From both application and scientific points of view, the ferromagnetic Heusler alloy system $\mathrm{Ni}_{50} \mathrm{Mn}_{25+x} \mathrm{Sb}_{25-x}$ is of great interest due to its shape memory properties resulting from its martensitic transformation. ${ }^{13}$ These properties are applicable in developing actuator materials. The $\mathrm{Ni}_{50} \mathrm{Mn}_{25+x} \mathrm{Sb}_{25-x}$ system also exhibits large magnetic entropy changes, which makes it a material to be considered for further studies related to the development of magnetic refrigerator working materials. ${ }^{14}$ In this work, we report the observation of $\mathrm{EB}$ in the bulk polycrystalline $\mathrm{Ni}_{50} \mathrm{Mn}_{25+x} \mathrm{Sb}_{25-x}$ $(12 \leqslant x \leqslant 13)$ Heusler alloy system. This observation is an important addition to the multifunctional properties of the $\mathrm{Ni}_{50} \mathrm{Mn}_{25+x} \mathrm{Sb}_{25-x}$ Heusler alloy system. The experimental results presented here might result in the outcome of important applications of the $\mathrm{Ni}_{50} \mathrm{Mn}_{25+x} \mathrm{Sb}_{25-x}$ system.

Approximately $5 \mathrm{~g}$ of polycrystalline buttons of $\mathrm{Ni}_{50} \mathrm{Mn}_{25+x} \mathrm{Sb}_{25-x}(12 \leqslant x \leqslant 13.5)$ were fabricated by conventional arc-melting methods. The combinations of elements ( $\mathrm{Ni} \mathrm{Mn}$, and $\mathrm{Sb}$ of $4 \mathrm{~N}$ purity) were repeatedly melted in an argon atmosphere. The weight loss of the resulting alloy, after melting, was found to be less than $0.2 \%$. For homogenization, the samples were wrapped in Ta foil and annealed in vacuum for $24 \mathrm{~h}$ at $850{ }^{\circ} \mathrm{C}$, and slowly cooled down to room temperature.

$\mathrm{X}$-ray diffraction measurements were conducted at room temperature using a mini materials analyzer x-ray diffractometer made by GBC Scientific Equipment, Inc. The diffrac-

\footnotetext{
a) Author to whom correspondence should be addressed; electronic mail: mkhan@siu.edu
}

tometer employed $\mathrm{Cu} K \alpha$ radiation and Bragg-Brentano geometry.

The magnetization measurements were performed in the temperature range of 5-400 $\mathrm{K}$ and in magnetic fields up to $5 \mathrm{~T}$, using a superconducting quantum interference device magnetometer made by Quantum Design, Inc. For ZFC measurements, the samples were cooled down from 380 to $5 \mathrm{~K}$ in zero magnetic field. For FC measurements, the samples were cooled down to $5 \mathrm{~K}$ from $380 \mathrm{~K}$ in applied magnetic fields ranging from 0.01 to $5 \mathrm{~T}$.

XRD patterns of all the $\mathrm{Ni}_{50} \mathrm{Mn}_{25+x} \mathrm{Sb}_{25-x}(7 \leqslant x \leqslant 13.5)$ samples obtained at room temperature suggest that the samples are of single phase and possess cubic $L 2_{1}(7 \leqslant x$ $\leqslant 12.5)$ and orthorhombic $(13 \leqslant x \leqslant 13.5)$ structures. The ZFC and FC magnetization curves as a function of temperature $[M(T)]$ of $\mathrm{Ni}_{50} \mathrm{Mn}_{25+x} \mathrm{Sb}_{25-x}(x=7,12,12.5,13.0,13.5)$ alloys obtained in a field of $0.01 \mathrm{~T}$ are shown in Fig. 1. As shown in Fig. 1(a), the only transition observed in both the ZFC and FC $M(T)$ curves of the alloy with $x=7$, is a sharp drop of magnetization at the ferromagnetic transition temperature $T_{C} \approx 363 \mathrm{~K}$. Below $T_{C}$ at around $345 \mathrm{~K}$, the ZFC and FC curves separate showing irreversible behavior [see inset of Fig. 1(a)]. Such splitting of the ZFC and FC $M(T)$ curves is due to the presence of $\mathrm{AF}$ exchange interaction in the system. ${ }^{15,16}$ The $\mathrm{Mn}$ in the $\mathrm{Sb}$ sites interacts antiferromagnetically with the Mn in the Mn sites inducing AF ex-

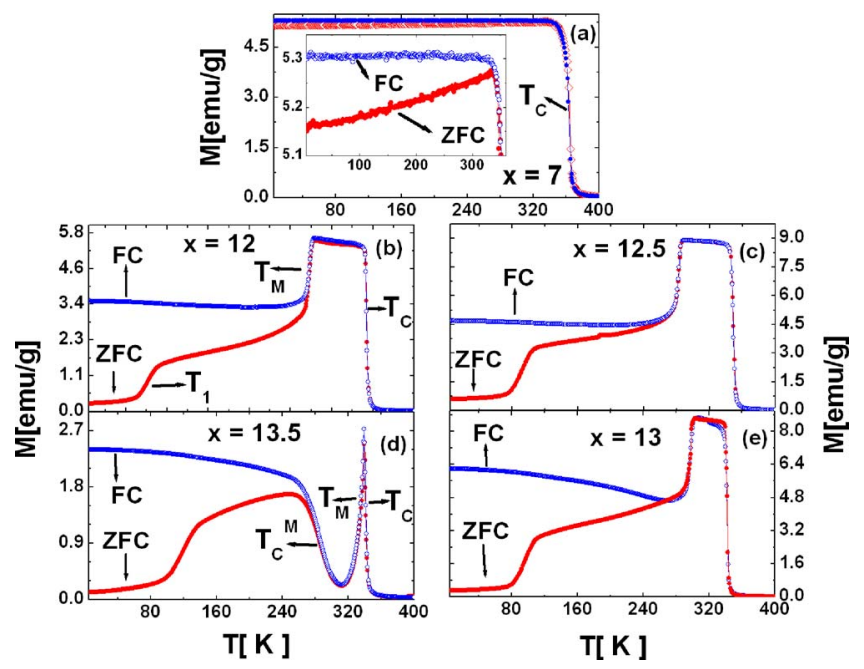

FIG. 1. Zero field and field cooled magnetization curves as a function of temperature of $\mathrm{Ni}_{50} \mathrm{Mn}_{25+x} \mathrm{Sb}_{25-x}$ obtained at a field of $0.01 \mathrm{~T}$. 


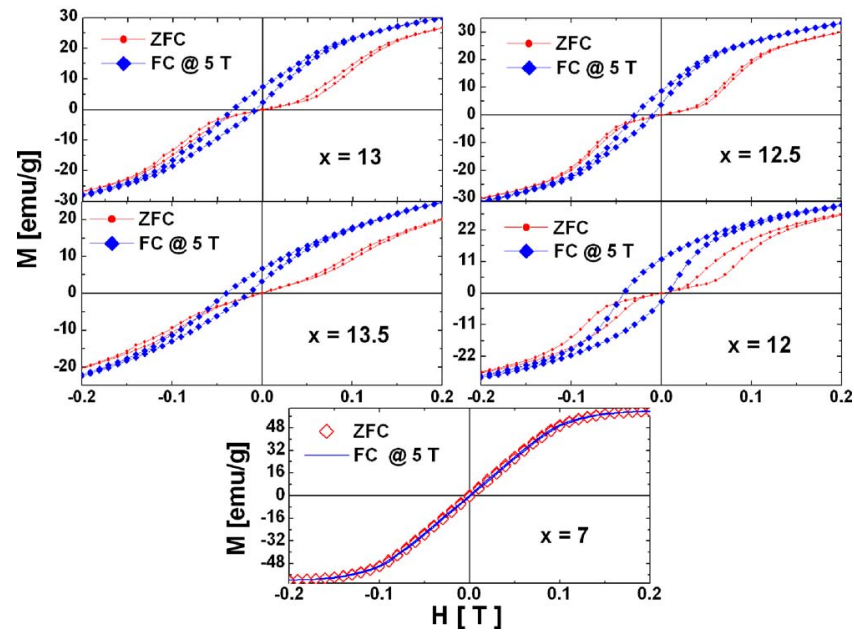

FIG. 2. Zero field and field cooled hysteresis loops of $\mathrm{Ni}_{50} \mathrm{Mn}_{25+x} \mathrm{Sb}_{25-x}$.

change in the system. The ZFC curves of the alloys with $x=12-13$ [see Figs. 1(b)-1(e)] show a sharp increase in magnetization at low temperature $(T<115 \mathrm{~K})$. We refer this transition temperature as the exchange bias blocking temperature, $T_{1}$. Usually, this temperature is defined as the temperature near which the EB effect vanishes in a system. ${ }^{17}$ Such characteristics are not observed in the FC curves of the alloys. Above a certain temperature, the alloys with $12 \leqslant x$ $\leqslant 13$ possess completely reversible FC and ZFC $M(T)$ curves where a steplike increase in magnetization is observed at the martensitic transformation temperature $T_{M},{ }^{15,16}$ followed by a decrease of magnetization at $T_{C}$ [see inset of Figs. 1(b) and 1(c)]. Before $T_{M}$, the FC and ZFC $M(T)$ curves of the alloy with $x=13.5$ show a transition at the ferromagnetic transition temperature $T_{C}^{M}$ of the martensitic phase [see Fig. 1(d)]. Details of such transitions are presented in Refs. 15 and 16. Figure 1 shows that the separation of the ZFC and FC $M(T)$ curves is much larger in the martensitic phase than it is in the austenitic phase. Such observations were also valid in the $\mathrm{Ni}-\mathrm{Mn}-\mathrm{In}$ and $\mathrm{Ni}-\mathrm{Mn}-\mathrm{Sn}$ systems, where such behaviors were justified by the different $\mathrm{AF}$ exchanges in the martensitic and austenitic phases. ${ }^{15,16}$ The $\mathrm{AF}$ in the martensitic phase is suggested to be stronger due to change in $\mathrm{Mn}-\mathrm{Mn}$ distances caused by the twinning of the martensitic phase. Figure 2 shows the ZFC and FC (cooling field, $H=5 \mathrm{~T}$ ) magnetization as a function of field $[M(H)]$ curves from -0.2 to $0.2 \mathrm{~T}$ of $\mathrm{Ni}_{50} \mathrm{Mn}_{25+x} \mathrm{Sb}_{25-x}$. The original curves were obtained from -2 to $2 \mathrm{~T}$ field due to the fact that saturation of magnetization takes place around $2 \mathrm{~T}$. For clear visualization of the shift of magnetization, curves from -0.2 to $0.2 \mathrm{~T}$ are shown. The alloy with $x=7$ shows no difference in the ZFC and FC curves. The figure clearly shows the shift of the FC hysteresis loops from the ZFC hysteresis loops of the alloys with $x>7$. This is a typical behavior observed in EB systems with FM-AF interfaces. The ZFC curves of the samples with $x>7$ shows double-shifted hysteresis loops that also signifies the EB effect in the system. These loops appear due to the AF region being divided, due to zero field cooling, into two types of regions locally oriented in the opposite direction. When the loops were obtained, each of these regions couples in opposite way to the FM regions resulting in double-shifted loop. A detail of this phenomenon is given in Ref. 17. For exploration of the temperature dependence of EB in $\mathrm{Ni}_{50} \mathrm{Mn}_{25+x} \mathrm{Sb}_{25-x}$ FC hyster-

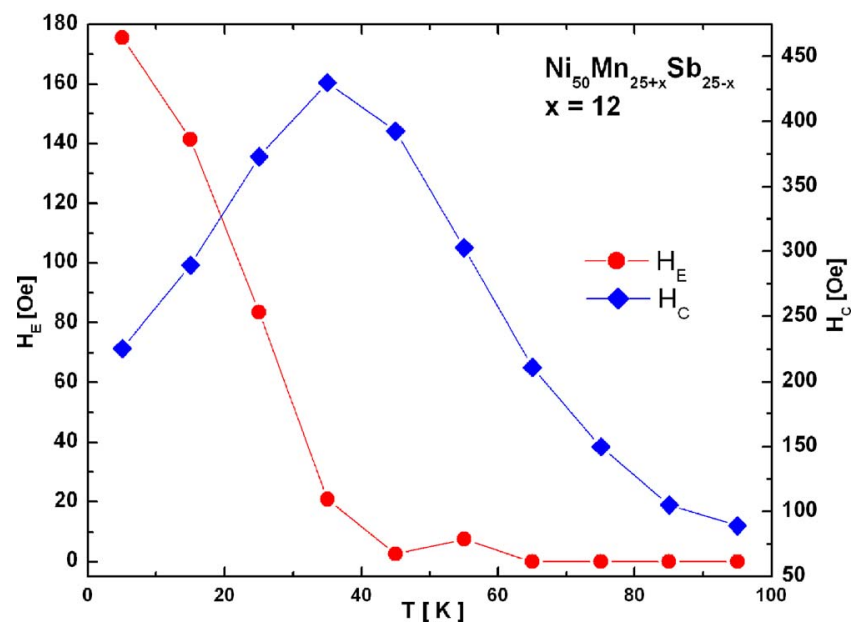

FIG. 3. Exchange bias field $\left(H_{E}\right)$ and coercivity $\left(H_{C}\right)$ as a function of temperature.

esis loops at temperatures from 5 to $95 \mathrm{~K}$ in $10 \mathrm{~K}$ increments were obtained for the alloy with $x=12$. The temperature dependence of $H_{E}$ and the coercivity $H_{C}$, evaluated from the hysteresis loops of the alloy with $x=12$ are shown in Fig. 3. It is found that the $H_{E}$ decreases as the temperature approaches $T_{1} \approx 75 \mathrm{~K}$, while the coercivity increases in the beginning and then starts decreasing as $H_{E}$ becomes zero. This behavior verifies that the EB phenomenon in the $\mathrm{Ni}_{50} \mathrm{Mn}_{25+x} \mathrm{Sb}_{25-x}$ system only exists for $T<T_{1}$. Figure 4 shows the plots of $T_{1}$ and $H_{E}$ at $5 \mathrm{~K}$ as a function of doping concentration $(x)$. It is evident in the figure that the $T_{1}$ and $H_{E}$ increase with increasing $\mathrm{Mn}$ concentration. $T_{1}$ increases from 78 to $123 \mathrm{~K}$ and $H_{E}$ increases from 174 to $248 \mathrm{Oe}$, as $x$ increases from 12 to 13.5 . The inset of Fig. 4 shows the linear dependence of $T_{1}$ and $H_{E}$ at $5 \mathrm{~K}$. Figure 5(a) shows the magnetization curves of the $\mathrm{Ni}_{50} \mathrm{Mn}_{25+x} \mathrm{Sb}_{25-x}$ system at $5 \mathrm{~K}$. It can be seen that the saturation moment decreases with increasing $\mathrm{Mn}$ concentration. Figure 5(b) shows that as the magnetic moment at $5 \mathrm{~T}$ decreases, $H_{E}$ increases, which suggests that $H_{E}$ is inversely proportional to saturation magnetization.

The observed experimental results clearly show the existence of $\mathrm{EB}$ in $\mathrm{Ni}_{50} \mathrm{Mn}_{25+x} \mathrm{Sb}_{25-x}$ system. The EB is ob-

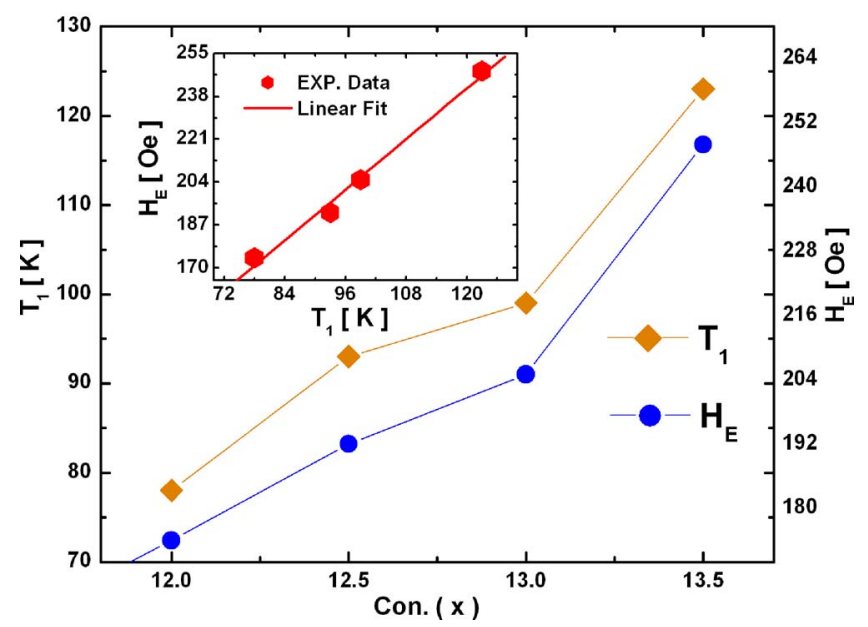

FIG. 4. Blocking temperature $\left(T_{1}\right)$ and bias field $\left(H_{E}\right)$ at $5 \mathrm{~K}$ as a function of doping concentration $(x)$ of $\mathrm{Ni}_{50} \mathrm{Mn}_{25+x} \mathrm{Sb}_{25-x}$. The inset shows $H_{E}$ as a function of $T_{1}$. 

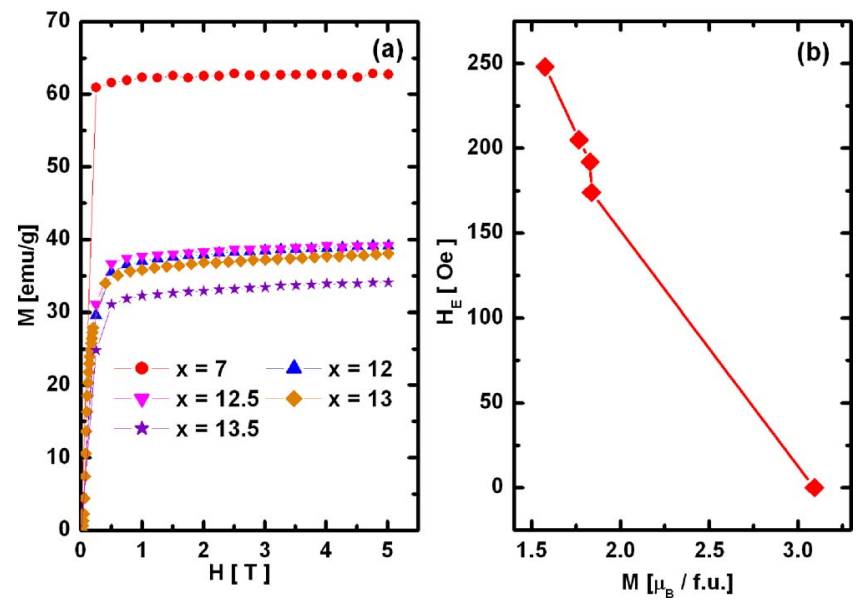

FIG. 5. (a) Magnetization curves at $5 \mathrm{~K}$ and (b) $H_{E}$ as a function of saturation magnetic moment of $\mathrm{Ni}_{50} \mathrm{Mn}_{25+x} \mathrm{Sb}_{25-x}$.

served only in the martensitic phases of the system. No EB is observed when the samples are in the austenitic phase (see Fig. 2), although presence of some AF exchange is suggested by the small separation of the ZFC and FC $M(T)$ curves. This could be due to the fact that the AF exchanges in not strong enough to result in the AF-FM interface necessary for EB to exist.

Exchange bias behavior has been observed in bulk polycrystalline $\mathrm{Ni}_{50} \mathrm{Mn}_{25+x} \mathrm{Sb}_{25-x}$ Heusler alloys. Shifts in the hysteresis loops of the samples occurred when the samples were cooled down to $5 \mathrm{~K}$ in an applied magnetic field of $5 \mathrm{~T}$. The observed EB phenomena in $\mathrm{Ni}_{50} \mathrm{Mn}_{25+x} \mathrm{Sb}_{25-x}$ are attributed AF-FM interfaces within the system that results from the coexistence of AF and FM exchange interactions. The EB property is an addition to the multifunctional properties of $\mathrm{Ni}_{50} \mathrm{Mn}_{25+x} \mathrm{Sb}_{25-x}$ Heusler alloy system.

This research was supported by the Research Opportunity Award from Research Corporation (RA0357) and by the Office of Basic Energy Sciences, Material Sciences Division of the U.S. Department of Energy (Contract No. DE-FG0206ER46291).

${ }^{1}$ W. H. Meiklejohn and C. P. Bean, Phys. Rev. 102, 1413 (1956).

${ }^{2}$ J. Nogués, D. Lederman, T. J. Moran, and Ivan K. Schuller, Phys. Rev. Lett. 76, 4624 (1996).

${ }^{3}$ S. Maat, K. Takano, S. S. P. Parkin, and Eric E. Fullerton, Phys. Rev. Lett. 87, 087202 (2001).

${ }^{4}$ M. R. Fitzsimmons, C. Leighton, J. Nogués, A. Hoffmann, Kai Liu, C. F. Majkrzak, J. A. Dura, J. R. Groves, R. W. Springer, P. N. Arendt, V. Leiner, H. Lauter, and Ivan K. Schuller, Phys. Rev. B 65, 134436 (2002). ${ }^{5}$ Miguel Kiwi, J. Magn. Magn. Mater. 234, 584 (2001).

${ }^{6}$ M. D. Stiles and R. D. McMichael, Phys. Rev. B 63, 064405 (2001).

${ }^{7}$ U. Nowak, K. D. Usadel, J. Keller, P. Miltényi, B. Beschoten, and G. Güntherodt, Phys. Rev. B 66, 014430 (2002).

${ }^{8}$ J. Nogués and I. K. Schuller, J. Magn. Magn. Mater. 192, 203 (1999).

${ }^{9}$ F. S. Luborsky, Electro-Technol. 107 (Sept. 1962).

${ }^{10}$ J. C. S. Kools, IEEE Trans. Magn. 32, 3165 (1996).

${ }^{11}$ A. E. Berkowitz and Kentaro Takan, J. Magn. Magn. Mater. 200, 552 (1999).

${ }^{12}$ R. L. Stamps, J. Phys. D 33, R247 (2000).

${ }^{13}$ Y. Sutou, Y. Imano, N. Koeda, T. Omori, R. Kainuma, K. Ishida, and K. Oikawa, Appl. Phys. Lett. 85, 4358 (2004).

${ }^{14}$ Mahmud Khan, Naushad Ali, and Shane Stadler, J. Appl. Phys. 101, 053919 (2007).

${ }^{15}$ Thorsten Krenke, Mehmet Acet, Eberhard F. Wassermann, Xavier Moya, Lluís Mañosa, and Antoni Planes, Phys. Rev. B 72, 014412 (2005).

${ }^{16}$ Thorsten Krenke, Mehmet Acet, Eberhard F. Wassermann, Xavier Moya, Lluís Mañosa, and Antoni Planes, Phys. Rev. B 73, 174413 (2006).

${ }^{17}$ Sebastian Brück, Jordi Sort, Vincent Baltz, Santiago Surinach, Juan Santiago Munoz, Bernard Dieny, Maria DolorsBaro, and Josep Nogues, Adv. Mater. (Weinheim, Ger.) 17, 2978 (2005). 